\title{
Mudanças no Marketing das Organizações Decorrentes do Uso de Plataformas de Redes Sociais: Casos brasileiros
}

\author{
Durval Lucas Jr. ${ }^{1}$, Cesar Alexandre de Souza ${ }^{2}$ \\ durval@ufscar.br, calesou@usp.br \\ ${ }^{1}$ Universidade Federal de São Carlos, Rod. João Leme dos Santos (SP-264), Km. 110, Prédio CCGT, sala 1152, \\ 18052-780, Sorocaba, Brasil \\ ${ }^{2}$ Universidade de São Paulo, Av. Prof. Luciano Gualberto, 908, 05508-010, São Paulo, Brasil
}

DOI: 10.17013/risti.18.83-98

Resumo: As plataformas de redes sociais são uma das principais tecnologias emergentes em empresas, ampliando o uso inicialmente concebido para pessoas físicas. Esta pesquisa tem como objetivo compreender implicações do uso dessas plataformas nas funções de marketing em organizações brasileiras do setor de comércio e serviços, utilizando estudos de casos múltiplos em quatro empresas líderes em seus segmentos. Entre os resultados obtidos, verificou-se que o uso de redes sociais gerou mudanças incrementais nas atividades de comunicação, seja com a reestruturação de fundamentos como mídia, conteúdo e dinâmica de resposta, seja com o efetivo compartilhamento de parte destas atividades com a nova área de redes sociais introduzida nas organizações. Mudanças no tocante à estrutura organizacional não foram observadas, enquanto que em relação aos sistemas préexistentes foi percebido um movimento de integração ainda em desenvolvimento.

Palavras-chave: Redes sociais, Marketing, Sistemas de Informação

\section{Changes in Marketing in Organizations Resulting from the Use of Social Networking Sites: Brazilian Cases}

\begin{abstract}
Social networking sites are one of the key emerging technologies in organizations, extending the original use for individuals. This research aims to understand implications of using social networking sites in marketing in Brazilian organizations in the trade and services sector, using the multiple case study in four organizations which are leaders in their market segments. Among the results, we observed that the use of social networking sites created incremental changes in the marketing communication activities, either with the restructuring of foundations such as media, content and dynamic response, either with the effective part of sharing these activities with the new area of social networks in organizations. Changes regarding the organizational structure weren't observed, whereas in relation to the existing systems integration there is a movement still in development.
\end{abstract}

Keywords: Social Networking Sites, Marketing, Information Systems 


\section{Introdução}

As plataformas de redes sociais (ou, simplesmente, "redes sociais") despontam como uma das principais tecnologias emergentes no universo organizacional, com a adesão de diversas organizações, numa ampliação do uso originalmente concebido para as pessoas físicas. Neste caso, o principal atributo que atrai as organizações é a velocidade que estes instrumentos possuem em relação a outros meios de comunicação com clientes/ consumidores, além de aspectos como a colaboração, o engajamento e a customização, somente possíveis por meio das plataformas Web 2.o. Do ponto de vista organizacional, são diversas as utilidades que as redes sociais possuem, com foco tanto em clientes e processos externos como internos, entre os quais: monitoramento do que se fala a respeito da organização e de seus concorrentes, com o consequente desenvolvimento de estratégias (Lucas Júnior \& Ornellas, 2012; Teixeira \& Azevedo, 2011); melhoria do grau de relacionamento com clientes e demais stakeholders (Lucas Júnior \& Souza, 2011); promoção da colaboração entre funcionários e melhorias na aprendizagem relacionada ao trabalho (Bingham \& Conner, 2010), bem como em pesquisa e inovação (Belo, Castela \& Fernandes, 2013) e novas práticas de gestão (McAffee, 2010).

Considerando estas utilidades e possibilidades, evidenciam-se as razões pelas quais as redes sociais estão cada vez mais presentes no cotidiano organizacional. Tal presença se materializa a partir de iniciativas como a criação de departamentos ou áreas específicas de redes sociais (Figueiró, 2010), ou como a contratação de profissionais dedicados ao tema, comumente conhecidos como analistas de redes/mídias sociais. Ainda que pese o fato de que o perfil destes profissionais esteja em processo de formação, tem-se como pressuposto a união de atribuições operacionais e estratégicas, dentre as quais "monitorar as redes sociais, pensando estratégias e executando ações para divulgar produtos e serviços, pesquisar o público-alvo e novas vertentes para o negócio e [...] responder a questões específicas de internautas" (Kopchitz, 2011). Okazaki e Taylor (2013) mostram-se otimistas ao discorrer sobre o uso corporativo de redes sociais: em seu estudo, destacam pesquisa realizada com as empresas integrantes do ranking Fortune 500 em 2012, das quais $73 \%$ possuíam uma conta corporativa no Twitter, enquanto $66 \%$ possuíam uma página corporativa no Facebook. Apesar dessa grande penetração no contexto organizacional, é importante observar a ressalva imposta por Sinclaire e Vogus (2011): apesar do rápido crescimento do uso de redes sociais pelas organizações, grande parte destas afirma que seu uso ainda está em fase experimental ou embrionária.

A partir desse contexto, tem-se como principal objetivo desta pesquisa compreender as implicações do uso de redes sociais na estrutura, nos processos e nos sistemas da área de marketing das organizações brasileiras do setor de comércio e serviços. Do ponto de vista teórico, este trabalho pretende contribuir ao discutir o processo de adaptação das estruturas organizacionais ao novo paradigma tecnológico e comunicacional trazido por estas plataformas. Além disso, possui o diferencial de tratar do uso de redes sociais em um país em desenvolvimento, fenômeno não demonstrado com frequência nas pesquisas realizadas no contexto das tecnologias emergentes. Para a prática das empresas, pretende-se contribuir com os gestores que desejam consolidar o uso corporativo de redes sociais no cenário organizacional, especialmente em áreas como o marketing que, mesmo possuindo um aparato tecnológico bastante diversificado à sua disposição, enfrenta crescentes desafios no tocante ao estabelecimento de vantagens competitivas, 
especialmente no tocante à comunicação com clientes/consumidores, processo que vem sendo continuamente afetado devido à diminuição das assimetrias de informação resultantes da ascensão das tecnologias sociais como a web 2.o.

\section{O uso da TI no marketing das organizações}

Não se pode afirmar que o uso de ferramentas tecnológicas seja uma novidade para o marketing, remontando à década de 1960 o uso dos primeiros sistemas de informação na área de marketing das organizações. Mesmo considerando que os gestores de marketing já sentiam a necessidade de informações mais apropriadas ao aumento da complexidade de seus negócios, Kotler (1966) afirmava que eram poucos os que faziam uso das ferramentas tecnológicas então disponíveis, destacando como iniciativas bem-sucedidas algumas desenvolvidas por organizações diretamente ligadas ao varejo, especialmente nas funções relacionadas ao contato com o cliente. Mais recentemente, Wierenga e Van Bruggen (2000) ratificaram esta perspectiva quando afirmaram que, ao se comparar a área de marketing com áreas como finanças e logística, por exemplo, percebe-se que a área de marketing é uma das que menos utiliza as tecnologias da informação em suas capacidades produtivas. Além disso, Trainor et al. (2011) questionam sobre a maneira pela qual os recursos de TI e marketing, combinados entre si, vêm gerando novas competências para as organizações, especialmente no tocante a melhorias de desempenho e construção de vantagens competitivas.

De acordo com Trainor et al. (2011), o que se percebe é a dificuldade das organizações em compreender de que maneira a informação derivada do uso da tecnologia é integrada e acessada pela organização para melhorar as funções de marketing, especialmente no tocante ao relacionamento com clientes e consumidores. Neste sentido, as transformações tecnológicas ocorridas desde a década de 1960 só vieram a impactar a área de marketing em meados da década de 1990, quando a explosão de dados e as tecnologias de rede pressionaram a área de marketing a assumir uma postura mais proativa, estratégica.

Outro ponto que merece destaque durante esse período é a falta de alinhamento entre as áreas de TI e de marketing. Percebe-se que esse fenômeno vem sendo construído ao longo do tempo, sendo que, entre as principais razões apresentadas pela literatura, estão:

- afalta depriorizaçãodaalocação dos recursos computacionais nafunçãodemarketing, já que as empresas possuíam poucos recursos computacionais disponíveis - e estes eram consequentemente caros - e outras áreas da organização foram percebidas como detentoras de resultados mais relevantes do uso das tecnologias;

- $\quad$ o espírito de independência que a área de marketing desenvolveu ao longo do tempo, reflexo principalmente do desenvolvimento das próprias aplicações tecnológicas, do uso de mão de obra externa à organização e, em parte, pela postura pouco familiarizada com as potencialidades que a tecnologia poderia oferecer.

Assim, a década de 2010 pode representar um novo momento com vistas a essa aproximação entre marketing e a área de TI, já que as empresas estão cada vez mais imersas em tecnologia, e as tecnologias sociais têm representado um novo horizonte de oportunidades para a área de marketing, que tem percebido como substanciais os benefícios da tecnologia no desempenho de suas funções e da organização como um todo. 


\section{O uso corporativo das redes sociais}

A ascensão das ferramentas Web 2.o representou a consolidação de um novo paradigma comunicacional, pois os usuários, até então receptores de conteúdo, passaram a ser também geradores e disseminadores de conteúdo (Li Y. \& Li T., 2013). Desta forma, as redes sociais passaram a ser o reflexo da nova etapa que se encontra a sociedade da informação, cada vez mais conectada, engajada e participativa. Segundo Kaufman (2010, p.30), "Web 2.o é um termo utilizado para definir a segunda geração da web, fortemente marcada pela interatividade, pelos conteúdos gerados por usuários, pela personalização de serviços e pela colaboração entre os internautas".

Benbunan-Fich (2002), por sua vez, afirma que um movimento de apropriação de uma tecnologia pode ser considerado bem-sucedido quando a organização consegue influenciar modificações no ambiente como um todo, mudando as regras de negócio existentes. Segundo a autora, a internet pode ser interpretada como um canal, devido à sua possibilidade de estreitamento dos relacionamentos entre a organização e seus stakeholders, especialmente seus clientes/consumidores.

Desta forma, os movimentos de apropriação das redes sociais podem ser um reflexo de como essas ferramentas tecnológicas são vistas pelas organizações. Esses movimentos também podem ser realizados de uma forma diferente daquelas vislumbradas pela gestão, o que levaria a discrepâncias entre o que a organização pensa que as redes sociais significam em seu contexto, com aquilo que de fato o são. Quanto mais fidedignos esses movimentos de apropriação são em relação à imagem que a organização faz das redes sociais, mais bemsucedido espera-se que sejam estes movimentos. Saldanha e Krishnan (2012), por sua vez, afirmam que são desafios associados à implantação de ferramentas Web 2.o as potenciais diferenças entre o processo de adoção e as habilidades das firmas em explorá-las.

Segundo Sinclaire e Vogus (2011), do ponto de vista mercadológico, as redes sociais também proporcionam alterações no equilíbrio do poder de barganha entre consumidores e organizações, já que estas ferramentas permitem que sejam compartilhadas diversas informações sobre produtos e serviços. Consequências dessa alteração, por exemplo, são as mudanças na estratégia corporativa, que passem a contemplar o uso destas plataformas visando ao restabelecimento do equilíbrio de tais forças.

Dentre as características apontadas pelos autores como motivadoras ao uso de redes sociais pelas organizações, estão a facilidade de implementação e a possibilidade de contato mais estreito com clientes e consumidores. Saldanha e Krishnan (2012), por sua vez, afirmam que o valor das aplicações web 2.0 para as organizações é incrementado quando estas plataformas estão conectadas e integradas com outros sistemas que existam na organização. Desta forma, a integração com processos de negócios e outras aplicações torna as empresas mais abertas à adoção de redes sociais.

Segundo Jue, Marr \& Kassotakis (2010), a implantação de redes sociais nas organizações pode ocorrer de três maneiras diferentes: disruptiva, gradativa ou emergente. A disruptiva é aquela ideal para organizações com grupos menores, e cuja implantação é feita ao mesmo tempo em toda a estrutura; a gradativa prevê a utilização de projetospiloto em departamentos cuja equipe esteja mais familiarizada com as ferramentas, tornando o processo de aprendizagem mais seguro, enquanto a emergente se aproveita 
das capacidades tecnológicas dos próprios funcionários, que acabam por estimular seus colegas de maneira espontânea, num ciclo de propagação semelhante ao dos virais.

Dutta e Fraser (2009) mostram que ainda há resistência das organizações no uso destas ferramentas, ainda que Belo et al. (2013) afirmem que os indivíduos esperam que as organizações estejam representadas nas redes sociais. O principal motivo, segundo Dutta e Fraser (2009), seria o conflito existenteentre os atuais modelos deestruturas organizacionais, rígidas e baseadas no controle e na hierarquia, e a essência das plataformas web 2.0, cujas características implicam em práticas mais sociais, horizontais e transparentes. A introdução de ferramentas web 2.o, neste sentido, acarretaria em modificações da estrutura de poder, o que desagrada especialmente a média gerência.

Ainda discorrendo sobre a interação entre organização e tecnologia, Hasgall e Shoham (2007) destacam que, ao mesmo tempo em que aplicações centralizadas se mantêm importantes no contexto organizacional, cresce a importância das ferramentas que promovem a socialização da informação, gerando maior transparência nos processos de gestão e maior empowerment dos funcionários, que passam a ter um maior engajamento em relação ao trabalho. O sucesso destas novas plataformas se dá justamente pela possibilidade de transformação do conhecimento tácito em explícito, ao mesmo tempo em que esse conhecimento se torna amplamente disponível e compartilhável. Importante observar que, até então, a tecnologia estava a serviço da manutenção dos processos de controle e do modelo hierárquico de estrutura: sistemas como ERP e CRM possuem como principal característica a centralização dos dados fornecidos pelas diversas áreas organizacionais, com vistas ao atendimento de necessidades específicas como a racionalização da gestão ou o desenvolvimento de estratégias de atendimento ao cliente (Hasgall \& Shoham, 2007).

\section{Metodologia e Procedimentos}

Este trabalho pode ser classificado como qualitativo, de natureza exploratória e de caráter descritivo. Do ponto de vista da prática da pesquisa, utilizou-se a técnica do estudo de caso, que "investiga um fenômeno contemporâneo dentro de seu contexto na vida real, especialmente quando os limites entre o fenômeno e o contexto não estão claramente definidos" (Yin, 2010, p.32).

Foram realizadas, entre os meses de dezembro de 2014 e abril de 2015, entrevistas em profundidade com os responsáveis pelas áreas de redes sociais de quatro organizações (BANCO, CONSTRUTORA, TELECOM e MOBURB, apresentadas adiante), em um total de 10 entrevistas. As empresas foram selecionadas a partir da constatação da sua presença e notável atuação nas redes sociais, de acordo com reportagens e premiações obtidas na imprensa especializada. As entrevistas foram realizadas com o apoio de roteiro semi-estruturado que compreendia os seguintes constructos, identificados no Referencial Teórico: a) Usos corporativos de redes sociais; b) Uso das TIC na área de Marketing; c) Integração das áreas de TI e Marketing; e d) Mudanças Organizacionais. Também foram consultados, em todos os casos, documentos institucionais, tais como manuais e relatórios, a fim de se caracterizar o processo de implantação das áreas de redes sociais e suas relações com as áreas de Marketing e TI. 
Todas as entrevistas foram transcritas e serviram com base para elaboração dos relatórios dos casos bem como a análise comparativa entre eles, de acordo com a orientação metodológica estabelecida por Miles e Huberman (1994), de promover a análise dos dados por meio de codificação dos constructos pré-definidos bem como de novos elementos identificados durante a pesquisa. A análise dos dados foi realizada com o auxílio do software NVIVO, versão 9.0.

\section{Análise Geral dos Casos}

\subsection{A área de Redes Sociais na estrutura organizacional}

Nos casos observados, a área de redes sociais possui diversas configurações dentro da estrutura organizacional, conforme descrito a seguir:

- No caso do BANCO, a área de redes sociais pertence à estrutura do Departamento de Canais Digitais, que congrega todos os canais de atendimento ao cliente, porém integrante de uma mesma diretoria que congrega o Departamento de Marketing. Ou seja, os Departamentos de Marketing e Canais Digitais possuem o mesmo status organizacional;

- No caso do MOBURB, uma empresa ligada a área de transportes e mobilidade urbana, a área de redes sociais pertence à estrutura do Departamento de Imprensa, este ligado à presidência da organização;

- No caso da CONSTRUTORA, a área de redes sociais pertence à estrutura da Diretoria de Marketing, mais especificamente na Gerência de Plataformas, integrante do Departamento de e-Business. Merece destaque o fato de que a área de redes sociais já foi autônoma em ocasião anterior, porém, após processo de reestruturação organizacional, voltou a ser integrante da Diretoria de Marketing;

- No caso da TELECOM, a área de redes sociais pertence à estrutura do Departamento de Canais Online, integrante da Diretoria de Comunicação Interna e Externa, pertencente, por sua vez, à Vice-presidência de Comunicação Corporativa. Na estrutura da TELECOM, o Departamento de Canais Online está no mesmo nível que o Departamento de Imprensa, e congrega não só as atividades de comunicação nas redes sociais, como também em demais mídias.

Desta forma, as diversas configurações observadas possuem em comum o fato de priorizarem o rápido acesso e disseminação da informação, bem como à agilidade de comunicação com os usuários e demais stakeholders, em detrimento de aspectos intraorganizacionais, tais como as demandas da área de Marketing, por exemplo. Isso não significa, porém, que haja uma desconexão da área de redes sociais com a área de Marketing nestas organizações, fato ratificado pelas diversas declarações dos entrevistados acerca de procedimentos e práticas quotidianas institu-cionalizadas, nos quais as duas áreas estão constantemente em contato. Em todos os casos observados, a área de redes sociais possui autonomia para definir seus principais procedimentos e atividades cotidianas. Porém, observou-se a existência de dois grupos distintos entre as organizações: enquanto nos casos do MOBURB e da TELECOM, a área de redes sociais 
está muito próxima às instâncias decisórias da organização (notadamente presidências e vice-presidências) implicando em autonomia relativa que se dá em função do tipo de conteúdo que deve ser veiculado, ou do teor da manifestação dos usuários, nos casos do BANCO e da CONSTRUTORA, a área de redes sociais não está tão próxima das instâncias decisórias, implicando em maior autonomia na realização de suas atividades.

\subsection{Usos corporativos de redes sociais}

A apropriação das redes sociais ocorreu de acordo com as peculiaridades do setor de mercado ou das operações internas, gerando diversos usos instrumentais. Nesse sentido, observou-se forte aderência do uso das redes sociais ao que descrevem Sinclaire e Vogus (2011) - quando o foco do uso é direcionado ao público externo às organizações - e também Jue et al. (2010) - que, por sua vez, tratam do engajamento dos funcionários no uso voltado ao público interno das organizações.

Isso pode ser ilustrado com o exemplo do Twitter, uma das duas plataformas utilizadas por todas as organizações pesquisadas. Mesmo considerando que nenhuma das organizações negligenciou a possibilidade de conversação direta com os usuários, a ampliação de seu uso se deu observando aspectos peculiares, tais como: enquanto nos casos do BANCO e da CONSTRUTORA, o uso do Twitter vislumbrava a promoção de seus produtos e serviços - com destaque para a CONSTRUTORA, que efetivamente chegou vender imóveis por meio desta plataforma -, nos casos do MOBURB e da TELECOM, o uso se dá com o objetivo de informar sobre eventos particulares do contexto organizacional, tais como o status da operação das linhas do MOBURB e os eventos apoiados pela TELECOM.

Outro exemplo, que ilustra restrições às quais as organizações estão submetidas, diz respeito ao Facebook: com exceção à TELECOM, que alegou razões estratégicas para não utilizá-lo, todas as organizações mencionaram, em algum momento das entrevistas realizadas, a dificuldade em lidar com os constantes aperfeiçoamentos e mudanças nas diretrizes de disseminação de conteúdo orgânico. Assim, BANCO e CONSTRUTORA passaram a desenvolver estratégias e mecanismos para incrementar suas postagens patrocinadas, enquanto o MOBURB considera o Facebook como a segunda plataforma mais importante em grau de utilização.

A realização de atividades que objetivam o fechamento efetivo de negócios foi o principal aspecto observado quando se compara o número de redes sociais em uso por cada uma das organizações pesquisadas. Ou seja, quanto mais premente a necessidade de se utilizar as redes sociais como mecanismo de fechamento de negócios, ou promoção direta de produtos e serviços, maior a diversificação de suas presenças organizacionais.

Assim, observou-se que, enquanto BANCO e CONSTRUTORA possuem presenças não só nas principais plataformas utilizadas, como também em plataformas especializadas em determinados nichos, MOBURB e TELECOM fazem um uso mais focado das plataformas, mantendo suas presenças apenas nas plataformas mais importantes para o alcance de seus objetivos no ambiente virtual. Ilustrando este raciocínio, o Quadro 1 apresenta quais plataformas foram identificadas como utilizadas pelas organizações integrantes desta pesquisa. 


\begin{tabular}{lcccc} 
& BANCO & MOBURB & CONSTRUTORA & TELECOM \\
\hline Facebook & $\checkmark$ & $\checkmark$ & $\checkmark$ & - \\
\hline Twitter & $\checkmark$ & $\checkmark$ & $\checkmark$ & $\checkmark$ \\
\hline YouTube & $\checkmark$ & - & $\checkmark$ & $\checkmark$ \\
\hline Instagram & $\checkmark$ & - & - & - \\
\hline LinkedIn & $\checkmark$ & - & $\checkmark$ & - \\
\hline Google+ & $\checkmark$ & - & $\checkmark$ & - \\
\hline Pinterest & - & $\checkmark$ & - & - \\
\hline Flickr & - & - & $\checkmark$ & - \\
\hline Waze & - & & \\
\hline
\end{tabular}

Quadro 1 - Redes sociais utilizadas pelas empresas pesquisadas

Sobre o histórico de utilização das plataformas pelas organizações, apresentado na Figura 1, observou-se que as iniciativas mais remontam ao ano de 2006, quando BANCO e CONSTRUTORA criam seus canais no YouTube e CONSTRUTORA cria o seu blog corporativo. Até então, não se possuem registros do uso efetivo de redes sociais pelas organizações pesquisas, à exceção do BANCO, que iniciou um trabalho de prospecção de sua marca no Orkut, mesmo que por meio do uso do perfil de um de seus colaboradores. A partir de 2008, efetivamente, começa a ocorrer um movimento de implantação das presenças organizacionais nas redes sociais, seguindo-se até o ano de 2013, quando CONSTRUTORA inicia suas ações de promoção no Waze e TELECOM cria sua company page no LinkedIn.

No que diz respeito a estratégias desempenhadas pelas organizações nas redes sociais, merece destaque a identificação - realizada especialmente por MOBURB e BANCO de perfis de usuários considerados influentes, com o objetivo de potencializar efeitos positivos e minimizar efeitos negativos que o uso das redes sociais possa causa às imagens corporativas e suas respectivas marcas. No contexto das organizações pesquisadas, apenas a CONSTRUTORA não alegou fazer uso explícito deste recurso; a estratégia da TELECOM constitui-se em utilizar os próprios funcionários e colaboradores como advogados da marca, inclusive vinculando-os aos conteúdos veiculados, enquanto BANCO e MOBURB desenvolvem estratégias concretas de identificação e contato com os usuários, estimulando-os e reconhecendo-os na medida em que desempenham suas atividades de defesa das marcas organizacionais.

Já no tocante às atividades prejudiciais à imagem das marcas, o MOBURB estabelece uma política de aproximação com usuários influentes e que possuem posturas consideradas prejudiciais: neste caso, o objetivo é diminuir a resistência dos usuários à marca, munindo-os de informações mais precisas sobre o quotidiano e o funcionamento organizacional, bem como apresentando suas potenciais demandas às instâncias decisórias da organização; o BANCO, por sua vez, estabeleceu e divulgou, em sua página na Internet, um Código de Conduta para as relações entre usuários: assim, a organização se sente respaldada a não responder eventuais atitudes agressivas, ou tratá-las de maneira apropriada; a TELECOM, por fim, não desenvolve mecanismos dedicados à relação com 
- BANCO inicia prospecções no Orkut;

- BANCO e CONSTRUTORA criam seus canais no YouTube; CONSTRUTORA cria seu Blog corporativo

- CONSTRUTORA cria perfil no Twitter

- BANCO, MOBURB e TELECOM criam seus perfis no Twitter

- BANCO cria sua página no Facebook

- BANCO e CONSTRUTORA criam suas páginas no Google+; MOBURB cria suas páginas no Facebook e Flickr

- BANCO cria suas páginas no Instagram e LinkedIn; MOBURB e TELECOM criam seus canais no YouTube

- CONSTRUTORA inicia ações de promoção no Waze; TELECOM cria sua company page no LinkedIn

Figura 1 - Histórico da implantação das redes sociais nas organizações pesquisadas.

usuários que possuam influência negativa nas redes sociais, por não considerar este fenômeno relevante em seu contexto organizacional.

Observou-se, ainda, que a prioridade das organizações pesquisadas é o desenvolvimento de atividades de comunicação de marketing, com foco tanto na promoção institucional e como na promoção de seus produtos e serviços. O caso do BANCO foi o único onde se verificou o desenvolvimento de serviços diretamente materializados no ambiente de uma plataforma de rede social, com a criação de um aplicativo que permite aos usuários clientes da organização a efetiva realização de operações financeiras dentro do ambiente do Facebook. Outra estratégia também identificada concerne às atividades de inteligência de marketing. Nesse contexto, destaca-se principalmente o caso da CONSTRUTORA, que usa deliberadamente as redes sociais para monitorar seus concorrentes, bem como detectar e antecipar movimentos do mercado. Isso não significa que BANCO, MOBURB e TELECOM não realizem atividades de inteligência de marketing nas redes sociais, porém essas atividades são realizadas com foco mais difuso, numa perspectiva muito mais voltada ao aperfeiçoamento e subsídio das atividades de relacionamento e geração de conteúdo - especialmente a busca por modelos e tendências que provoquem maior engajamento nos usuários.

\subsection{Uso da TI na área de Marketing}

No que diz respeito aos sistemas de informação de marketing existentes nas organizações pesquisadas, observou-se um equilíbrio entre sistemas desenvolvidos internamente pelas organizações e sistemas adquiridos de terceiros. Assim, BANCO e MOBURB pertencem ao grupo das organizações que desenvolveram suas próprias aplicações, enquanto A CONSTRUTORA faz parte das organizações que fazem uso de aplicação desenvolvida por terceiros, neste caso o Microsoft Dynamics, juntamente com o MOBURB, que 
parametrizou o Sugar, plataforma ERP baseada em software livre. A TELECOM não relatou o uso de sistemas desta natureza.

Também neste item verificou-se a existência de sistemas gerenciadores de redes sociais. A única exceção foi o caso da TELECOM, que ainda mantém o controle das atividades nas redes sociais com a utilização de planilhas eletrônicas online, conectadas com as agências responsáveis pelas atividades de monitoramento e avaliação de performance.

Sobre as bases de dados utilizadas pela área de Marketing das organizações pesquisadas, observou-se que há semelhança entre as principais fontes de dados utilizadas, bem como dos usos que são feitos destas fontes. Nos casos de MOBURB, CONSTRUTORA e TELECOM, constatou-se a predominância do uso de clippings e relatórios de imprensa, utilizados para monitorar a imagem da organização e aspectos do ambiente de mercado que dizem respeito a cada contexto organizacional. As principais peculiaridades observadas nesse contexto se devem ao uso de fontes alternativas de dados por algumas organizações, tais como a realização de pesquisas periódicas - qualitativas de opinião, e conjunturais, como a Pesquisa Origem-Destino - por parte do MOBURB, e da colaboração de usuários por meio de plataformas de crowdsourcing - com vistas principalmente ao desenvolvimento e aperfeiçoamento de inovações - observadas no caso da CONSTRUTORA. No caso do BANCO, em função de seu contexto organizacional, este fenômeno não pôde ser observado.

Observandoacaracterizaçãodaáreademarketingquantoaousoestratégicodeferramentas tecnológicas, merece destaque o caso da CONSTRUTORA, onde ficou evidenciado que, tanto no contexto intraorganizacional, quanto no contexto de seu segmento de mercado, a área de Marketing vem sendo considerada um elemento diferencial competitivo da organização. Internamente, a área de Marketing é reconhecida pelas demais áreas da organização como um ator relevante quando se trata da introdução de novas tecnologias, o que também lhe confere a posição de ser uma das principais portas de entrada de inovações no contexto organizacional. Por fim, a estruturação de uma comunicação multicanais confere maior versatilidade à organização, que pode responder aos diversos estímulos e demandas do mercado de maneira mais ágil e dinâmica.

No que diz respeito à integração dos sistemas de informação de marketing com as redes sociais, observou-se que apenas em uma das organizações observadas há a integração efetiva entre o sistema CRM utilizado e o sistema gerenciador de redes sociais. No caso da CONSTRUTORA, não só há a integração efetiva entre as aplicações tecnológicas, como o uso integrado destas aplicações é visto como vantagem competitiva no processo de relacionamento com os clientes, já que permite a identificação dos usuários que interagem com a organização via redes sociais, subsidiando na rápida tomada de decisões acerca de suas demandas. Por outro lado, no caso da TELECOM, este fenômeno específico não pôde ser discutido em função da inexistência de uso de sistemas gerenciadores de redes sociais.

Embora BANCO e MOBURB também compreendam a importância da integração entre as aplicações tecnológicas, e os impactos positivos que uma integração desse gênero traria para seus contextos organizacionais, aspectos como uma política organizacional de segurança da informação extremamente rígida, e a limitação de capacidade operacional do sistema CRM atualmente utilizado foram as razões apresentadas, respectivamente, 
para a ausência da integração entre essas aplicações. Assim, enquanto o BANCO acaba utilizando os sistemas de maneira totalmente desvinculada, aplicando procedimentos manuais de busca ou inserção de ocorrências entre os dois sistemas - especialmente no caso de reclamações que precisam ser registradas e/ou acompanhadas -, o MOBURB optou pela elaboração de procedimentos de exportação de dados, que podem ser aproveitados por áreas de negócio que demandem pelos dados oriundos das redes sociais.

\subsection{Integração das áreas de TI e Marketing}

No que diz respeito ao grau de suporte da área de TI aos sistemas de informação de marketing existentes nas organizações pesquisadas, observou-se de dois contextos distintos: enquanto que, nos casos do BANCO e do MOBURB, a área de TI é responsável não só pelo desenvolvimento ou customização dos sistemas utilizados, como também pela manutenção quotidiana destes sistemas, nos casos da CONSTRUTORA e da TELECOM a área de Marketing é a própria responsável pelo gerenciamento de suas aplicações.

Merece destaque o comportamento observado nos casos da CONSTRUTORA e TELECOM, em que a razão identificada para a maior autonomia da área de Marketing em relação ao uso dos sistemas de informação é o contexto do próprio negócio: devido ao fato de serem organizações ligadas a atividades de engenharia (civil e de telecomunicações, respectivamente), a área de TI acaba sendo responsável prioritariamente pelo gerenciamento da infraestrutura tecnológica das atividades ligadas ao core business, ficando a cargo das áreas de negócio que compreendem atividadesmeio o desenvolvimento e a manutenção de suas próprias aplicações. Ainda assim, mesmo nesse grupo de organizações, a área de TI não está totalmente desvinculada das atividades da área de Marketing, pois acaba exercendo papel importante na origem das soluções tecnológicas, seja pelo fechamento de amplas parcerias corporativas - como no caso da CONSTRUTORA, cuja parceria com a Microsoft influenciou na mudança do sistema CRM então utilizado -, seja pela certificação de fornecedores habilitados a fornecer soluções e serviços de tecnologia, como no caso da TELECOM.

No caso das aplicações tecnológicas dedicadas às atividades de redes sociais, apenas no caso do MOBURB foi identificada uma participação ativa da área de TI na origem deste tipo de aplicação, dada em função de sua característica organizacional: por ser uma organização pública, com processos de aquisição de produtos e serviços serem mediados unicamente via processos de licitação, a aquisição do sistema gerenciador de redes sociais se deu obrigatoriamente com a mediação da área de TI, única habilitada para o estabelecimento dos contratos ligados à tecnologia. Já nos casos do BANCO e da CONSTRUTORA, todo o processo de contratação do sistema gerenciador de redes sociais foi feito diretamente pela área de redes sociais, de modo que a área de TI aparece apenas como fornecedora da infraestrutura tecnológica necessária ao funcionamento das aplicações no ambiente organizacional. A TELECOM, por sua vez, foi a única das organizações pesquisadas a não utilizar sistemas gerenciadores de redes sociais, utilizando apenas aplicações como planilhas eletrônicas. Isso se dá devido ao fato de que as atividades de monitoramento e avaliação de performance são executadas por organizações parceiras - no caso, agências contratadas para este fim. 


\subsection{Mudanças organizacionais decorrentes do uso de redes sociais}

No que diz respeito ao contexto de implantação das áreas de redes sociais dentro das organizações pesquisadas, observou-se que, enquanto no caso do BANCO, o processo de apropriação das redes sociais culminou com a consolidação de uma estrutura independente, e com grande autonomia operacional, no caso da CONSTRUTORA, o movimento se deu no sentido inverso, passando de uma estrutura totalmente dedicada ao gerenciamento das atividades nas redes sociais, para uma estrutura integrada aos demais canais digitais da organização. Nos casos do MOBURB e da TELECOM, por sua vez, as áreas de redes sociais, uma vez estabelecidas, estiveram sempre incorporadas a departamentos já existentes. Note-se que, no contexto destas últimas organizações, a área de redes sociais está ligada à área de imprensa ou comunicação corporativa, aspecto que pode vir a denotar uma visão instrumentalista do uso das redes sociais por parte destas organizações.

Outro aspecto observado nos casos pesquisados diz respeito aos elementos que subsidiaram a implantação da presença organizacional nas redes sociais. Apenas no caso do BANCO foi observada a aparição de um empreendedor intraorganizacional, acarretando numa perspectiva bottom-up. No caso da CONSTRUTORA, apesar de a organização também poder ser considerada um exemplo de uso da perspectiva bottomup, observou-se que isto se dá muito mais pela autonomia operacional que a Gerência de Plataformas possui do que pela existência de empreendedores intraorganizacionais, tais como constatado no BANCO. Nas demais organizações pesquisadas, consequentemente, constatou-se que o movimento de apropriação das redes sociais se deu numa perspectiva top-down, seja com a determinação expressa de um gestor na criação dos perfis, sem que houvesse uma preparação específica para tanto - como no caso específico do MOBURB, seja pela orientação institucional vinda da reestruturação de planos de comunicação de marketing, como ocorrido na TELECOM.

O desenvolvimento das competências necessárias à realização das atividades nas redes sociais não ocorreu de maneira uniforme em todas as organizações pesquisadas. Enquanto que, no caso da CONSTRUTORA, destaca-se o fato de ter havido a contratação de um profissional especializado em redes sociais durante o processo de criação da estrutura voltada ao desempenho destas atividades, nos casos do BANCO e do MOBURB este processo se deu pelo próprio desenvolvimento das competências internas do pessoal das organizações, em uma abordagem próxima ao que se conhece como "tentativa e erro". Já no caso da TELECOM, pôde-se observar que, devido ao fato de o processo de implantação da área de redes sociais se deu mais recentemente, o desenvolvimento destas competências se deu por meio da contratação de um projeto de consultoria, no qual a empresa especializada, durante o período de um ano em que o projeto foi implantado, forneceu aos colaboradores internos todas as competências necessárias ao desenvolvimento corrente de suas atividades.

No que diz respeito à dinâmica da estrutura da área de marketing após a implantação das redes sociais, observou-se que, nas organizações pesquisadas, poucas alterações de caráter substancial foram encontradas. Isso se deve ao fato de que as áreas de redes sociais, uma vez implantadas, só estavam diretamente subordinadas à área de Marketing no caso da CONSTRUTORA. Assim, observou-se um aperfeiçoamento de processos 
internos, como os ligados à comunicação de marketing, o estabelecimento de processos vinculantes entre as duas áreas, mas pouco se observou efetivamente no que concerne a mudanças estruturais. Nos casos de BANCO e MOBURB, especificamente, observou-se a cessão de colaboradores da área de Marketing para as recém-criadas áreas de redes sociais, com vistas ao aperfeiçoamento de processos internos e à institucionalização de uma proximidade maior entre as duas áreas.

Reloativamente aos processos organizacionais criados a partir do uso das redes sociais, pôde-se observar uma ampla estruturação em todas as organizações pesquisadas. Nos casos de BANCO, MOBURB e TELECOM, constatou-se a existência de instrumentos de formalização destes processos, como manuais de procedimentos e guias para atividades específicas. No caso da CONSTRUTORA, por sua vez, a estruturação dos processos voltados às redes sociais é creditada à experiência de seus colaboradores e ao tempo de casa que estes possuem, inexistindo instrumentos que estabeleçam a sua formalização.

As atividades de relacionamento com os usuários se mostraram prioritárias nas organizações pesquisadas. Em função do tamanho de sua estrutura dedicada às atividades nas redes sociais, o BANCO foi a única organização pesquisada a possuir um esquema de atendimento que funciona 24 horas por dia, 7 dias por semana. Ainda no que diz respeito às atividades de relacionamento com os usuários, no caso do BANCO, especificamente, observou-se maior flexibilidade na linguagem utilizada para a interação com os usuários, ainda que sejam obedecidos os princípios gerais do atendimento, estabelecidos em manuais e diretrizes organizacionais; nos casos de MOBURB e TELECOM, as próprias postagens possuem esquemas de padronização, não só em função da resposta que deve ser dada ao usuário, como também em função do tipo de linguagem a se utilizar.

Os processos de monitoramento existentes nas organizações pesquisadas buscam, prioritariamente, captar a imagem destas organizações no ambiente virtual, bem como subsidiá-las na elaboração de conteúdos que serão veiculados nas redes sociais. Apesar de todas as organizações possuírem, em algum grau, atividades de monitoramento voltadas à inteligência de marketing, apenas a CONSTRUTORA alegou desenvolver um monitoramento com dedicação às atividades de inteligência de marketing, tais como análise de concorrentes e de tendências do mercado.

Especificamente no tocante às métricas referentes às atividades desenvolvidas pelas áreas de redes sociais, observou-se que todas as organizações pesquisadas priorizam métricas que indiquem o nível de engajamento dos usuários em relação aos seus perfis e, consequentemente, às suas marcas. Estas métricas podem ou não estar diretamente ligadas a métricas de atendimento: nos casos de BANCO e MOBURB, há a avaliação sistemática destes dois conjuntos de métricas, fator que, inclusive, subsidia a concessão dos prêmios com que as organizações foram agraciadas; nos casos de CONSTRUTORA e TELECOM, por sua vez, o foco é central na perspectiva do engajamento dos usuários, avaliado prioritariamente por meio da análise de quais conteúdos veiculados nas redes sociais influenciam no aumento dos níveis de navegação dos usuários nos perfis das organizações, e na eventual navegação dos usuários entre as plataformas.

Por fim, no que concerne aos processos da área de marketing afetados pela implantação das redes sociais, observou-se que as organizações pesquisadas tiveram mudanças significativas no processo de comunicação de marketing, não só pela adoção das 
redes sociais como novo veículo de mídia, como também pela própria necessidade de reestruturação de alguns fundamentos deste processo - como a busca por uma nova linguagem, o emprego de maior velocidade na elaboração e veiculação de conteúdos, e a necessidade de forte observação das tendências predominantes no ambiente das redes sociais - além dos próprios procedimentos internos, como os necessários à elaboração de conteúdos, à avaliação sistemática do impacto das postagens, e a necessidade de maior trânsito de informação com as demais áreas de negócio.

Especialmente nos casos do BANCO, do MOBURB e da TELECOM, observou-se a importância que a implantação das redes sociais vem adquirindo com vistas a uma flexibilização, ou mesmo uma mudança, em suas linguagens corporativas. Por serem organizações com maior viés burocrático, seja pelo seu tamanho, seja pelos segmentos de mercado em que atuam, estas organizações eram reconhecidas pela imagem mais distante de seus clientes/consumidores. Com a adoção de estratégias de comunicação institucional estruturadas nas redes sociais, houve a necessidade de criação de conteúdos específicos para estas plataformas, numa linguagem mais dinâmica e contemporânea, adequada ao perfil dos usuários. Isso vem resultando, na percepção das próprias organizações, em uma maior aproximação com os usuários e, consequentemente, numa percepção mais positiva a respeito de suas imagens organizacionais.

\section{Conclusões}

Esta pesquisa teve como principal objetivo compreender as implicações do uso de redes sociais na estrutura, nos processos e nos sistemas da área de marketing das organizações brasileiras do setor de comércio e serviços. Para tanto, utilizou-se o estudo de casos múltiplos, numa perspectiva qualitativa, exploratória e descritiva, contemplando quatro organizações líderes em seus segmentos de mercado, sendo elas: BANCO (serviços financeiros), MOBURB (transporte público), CONSTRUTORA (construção civil) e TELECOM (telecomunicações).

Pode-se afirmar que o uso de redes sociais gerou mudanças predominantemente incrementais, principalmente no que diz respeito aos processos da área de Marketing, com destaque para as atividades de comunicação de marketing, seja com a reestruturação de fundamentos como mídia, conteúdo e dinâmica de resposta, seja com o efetivo compartilhamento de parte destas atividades com a nova área de redes sociais que foi introduzida nas organizações. Mudanças no tocante à própria estrutura da área de marketing não foram observadas, enquanto que em relação aos sistemas de informação de marketing, existe um movimento de integração ainda em desenvolvimento.

Foram corroborados, por meio das evidências observadas nos casos integrantes desta pesquisa, os seguintes argumentos apresentados no Referencial Teórico:

- De Jue et al. (2010), que afirmam que o processo de implantação das redes sociais tem ocorrido de maneira gradativa ou emergente;

- De Lucas Júnior e Ornellas (2012), que afirmam que as redes sociais vêm auxiliando no monitoramento da imagem organizacional; e

- De Trainor et al.(2011), que afirmam que as redes sociais auxiliam as organizações na compreensão acerca da importância da informação para a área de marketing.

Também merece destaque o fato de que o uso estratégico das redes sociais acabou não sendo contemplado nesta pesquisa, principalmente devido ao processo de apropriação 
observado nas organizações pesquisadas ainda estar em seus estágios iniciais. Tratase de um movimento condizente não só com o uso destas plataformas, mas também com o uso de ferramentas tecnológicas de modo geral, já que as organizações costumam utilizá-las primeiramente com objetivos operacionais, para que então sejam utilizadas com objetivos estratégicos. (Os autores agradecem o financiamento concedido pela Fundação CAPES, Ministério da Educação, Brasil).

\section{Referências}

Belo, A., Castela, G. \& Fernandes, S. (2013). Ambientes Colaborativos Virtuais: potencial das redes sociais. O caso das empresas do Algarve, RISTI - Revista Ibérica de Sistemas e Tecnologias de Informação, 12, 65-79, DOI 10.4304/risti.12.65-79.

Bingham, T \& Conner, M. (2010). The new social learning: a guide to transforming organizations through social media. San Francisco: Berrett-Koehler Publishers, Inc.

Benbunan-Fich, R. (2002). Information technology in organizations: paradigms and metaphors, CIS Working Paper Series, 1, 1-24. New York: City University of New York (Zicklin School of Business).

Dutta, S. \& Fraser, M. (2009). Web 2.0: the ROI case, Chief Executive, 22 de jun. Disponível em < http://chiefexecutive.net/web-2-o-the-roi-case/> . Acessado: 10 ago 2014.

Figueiró, T. (2010). Empresas aderem a redes sociais sem envolver departamentos de TI, ComputerWorld, 25 jan. Disponível em <http://www.computerworld.com. pt/2010/o1/25/empresas-aderem-a-redes-sociais-sem-envolver-departamentosde-ti/>. Acessado: 04 ago 2014.

Hasgall, A. \& Shoham. (2007). S. Digital social network technology and the complex organizational systems, VINE: the journal of information and knowledge management systems, 37(2), 80-191. DOI 10.1108/03055720710759955.

Jue, A. L., Marr, J. A. \& Kassotakis, M. E. (2010). Mídias sociais nas empresas: colaboração, inovação, competitividade e resultados. São Paulo: Ed. Évora.

Kopschitz, I. (2011). Analista de redes sociais, um profissional do presente. O Globo, 27 set. Disponível em <http://oglobo.globo.com/emprego/analista-de-redes-sociaisum-profissional-do-presente-2747776> Acessado: 12 ago 2014.

Kotler, P. A. (1966). Design for the firm's marketing nerve center, Business Horizons, 9, 63-74. DOI 10.1016/0007-6813(66)90007-3.

Li, Y. M. \& Li, T. Y. (2013). Deriving market intelligence from microblogs, Decision Support Systems, 55(1), 206-217. DOI 10.1016/j.dss.2013.01.023.

Lucas Júnior, D. \& Ornellas, R. S. (2012). Using social networking sites (SNS) for environmental scanning: an analysis of content monitoring tools. Americas Conference on Information Systems 2012. Seattle, WA, USA.

Lucas Júnior, D. \& Souza, C. A. (2011). Estabelecendo estratégias de comunicação integrada de marketing nas redes sociais, Revista Pensamento e Realidade, 28(3), 45-6o. 
McAffee, A. (2010). Empresas 2.0: a força das mídias colaborativas para superar grandes desafios empresariais. Rio de Janeiro: Elsevier.

Miles, M. B.; Huberman, M.A. (1994). Qualitative data analysis: an expanded sourcebook. 2nd ed. Thousand Oaks: SAGE.

Saldanha, T. V. \& Krishnan, M. S. (2012). Organizational adoption of web 2.0 technologies: an empirical analysis, Journal of Organizational Computing and Electronic Commerce, 22(4), 301-333. DOI 10.1080/10919392.2012.723585.

Sinclaire, J. K., Vogus, C. E. (2011). Adoption of social networking sites: an exploratory adaptive structuration perspective for global organizations, Information Technology and Management, 12(4), 293-314. DOI 10.1007/s10799-011-0086-5.

Teixeira, D. \& Azevedo, I. (2011). Análise de opiniões expressas nas redes sociais, RISTI - Revista Ibérica de Sistemas e Tecnologias de Informação, 8, 53-65, DOI 10.4304/risti.8.53-65.

Trainor, K. J., Rapp, A., Beitelspacher, L. S. \& Schillewaert, N. (2011). Interacting information technology and marketing: an examination of the drivers and outcomes of e-Marketing capability, Industrial Marketing Management, 40, 162-174. DOI 10.1016/j.indmarman.2010.05.001.

Wierenga, B. \& Van Bruggen, G. (2000). Marketing management support systems: principles, tools, and implementation. Boston/EUA: Kluwer Academic Publishers.

Yin, R. K. (2010). Estudo de caso: planejamento e métodos, $2^{\mathrm{a}}$ edição. Porto Alegre: Bookman. 